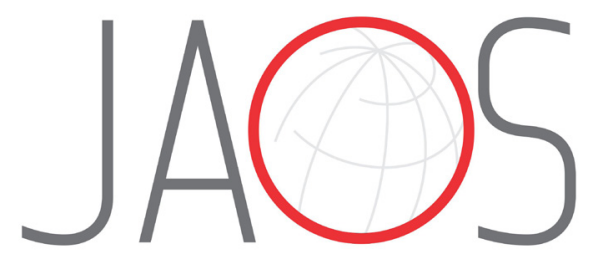

\title{
Temporomandibular joint disc displacement with reduction: a review of mechanisms and clinical presentation
}

\section{Abstract}

Rodrigo Lorenzi POLUHA ${ }^{1}$

Giancarlo De la Torre CANALES ${ }^{1}$

Yuri Martins COSTA ${ }^{2}$

Eduardo GROSSMANN ${ }^{3}$

Leonardo Rigoldi BONJARDIM ${ }^{4}$

Paulo César Rodrigues CONTI ${ }^{1}$
Submitted: April 11, 2018 Modification: September 4, 2018

Accepted: October 2, 2018
'Universidade de São Paulo, Faculdade de Odontologia de Bauru, Departamento de Prótese, Grupo de Dor Orofacial de Bauru, Bauru, São Paulo, Brasil. Fisiológicas, Piracicaba, São Paulo, Brasil.

${ }^{3}$ Universidade Federal do Rio Grande do Sul, Faculdade de Odontologia, Departamento de Ciências Morfológicas, Porto Alegre, Rio Grande do Sul, Brasil.

${ }^{4}$ Universidade de São Paulo, Faculdade de Odontologia de Bauru, Departamento de Ciências Biológicas, Seção de Fisiologia da Cabeça e da Face, Bauru, São Paulo, Brasil. 


\section{Introduction}

According to the American Academy of Orofacial Pain, temporomandibular disorder (TMD) is defined as a group of disorders involving the masticatory muscles, the temporomandibular joint (TMJ), and the associated structures. ${ }^{1}$ The most common TMJ conditions are pain-related and intra-articular disorders. ${ }^{2}$ Intraarticular disorders of the TMJ have been defined as an abnormal positional relationship between the disc and the condyle, articular eminence, and/or articular fossa. ${ }^{3}$

Among the intra-articular disorders of the TMJ, disc displacement with reduction (DDWR) corresponds to $41 \%$ of TMD clinical diagnoses. ${ }^{4}$ Also, DDWR can occur in $33 \%$ of asymptomatic individuals. ${ }^{5}$ In patients with DDWR, when the mouth is closed, the articular disc is displaced in relation to the condyle and, when the mouth is open, the disc returns to the intermediate area between the condyle and the articular tubercle ${ }^{1,6}$ (Figure 1).

Although the disc can be displaced in any direction (i.e., anterior, posterior, lateral, or medial), posterior and pure sideways displacements seem to be rare, whereas anterior displacement appears to be the most common. ${ }^{8}$ After the disc reduces during condylar translation, the range of motion is not limited; however, mandibular movements may not be as smooth as in a regular condition because of the momentary sliding of the condyle on and off of the disc. ${ }^{9}$ Notwithstanding, once the mouth opening position is achieved, the final position of the condyle and the disc of a joint with DDWR is almost identical to one without displacement. ${ }^{10}$

Clinically, DDWR is related to TMJ noise. ${ }^{11}$ The movement of the disc onto and off may result in a clicking, snapping, and/or popping sound known as opening and closing click $^{12}$ (Figure 2). TMJ clicking corresponds to $26.2 \%$ of clinical signs of TMD and is one of the most common complaints of patients. ${ }^{13}$ Self-report of TMJ clicking are more frequent in careseeking patients that also have greater non-specific physical symptoms, with a propensity to somatization and with the heightened awareness of their own body image. ${ }^{14}$

The correlation between joint pain, known as arthralgia, and disc position is still a matter of debate. ${ }^{15}$ Although most cases of DDWR are not accompanied by pain, some sort of joint inflammation may occur and cause painful symptoms; ${ }^{9}$ even those asymptomatic DDWR joints can present some sensitization level. A study evaluating the pressure pain threshold (PPT), showed that individuals with asymptomatic DDWR had significant lower PPT values than individuals with a proper disc/condyle relationship ( $1.64 \pm 0.40 \mathrm{kgf} /$ $\mathrm{cm}^{2}$ and $2.35 \pm 0.56 \mathrm{kgf} / \mathrm{cm}^{2}$, respectively), which indicates that, despite the adaptive tissue capacity of the individual with DDWR, there is a certain degree of modification in the response to the pressure application. ${ }^{16}$ This fact, however, is not per se indicative of the need for therapy.

DDWR is a highly prevalent clinical condition ${ }^{4}$ that still raises many doubts to patients and clinicians regarding the true risk involved in the disorder, odds of progression and need for treatment. Therefore, this literature review aimed at addressing the recent advances in the etiology, epidemiology, diagnosis, natural course, and management of DDWR.

\section{Methodology}

A non-systematic search was conducted to identify articles related to the etiology, epidemiology, diagnosis, and treatment of DDWR. To this goal, searches within the PubMed, Scopus, SciELO, Medline, LILACS and Science Direct were performed using the Medical Subjective Headings (MeSH) terms "temporomandibular disorders", "temporomandibular joint", "disc displacement", and "disc displacement with

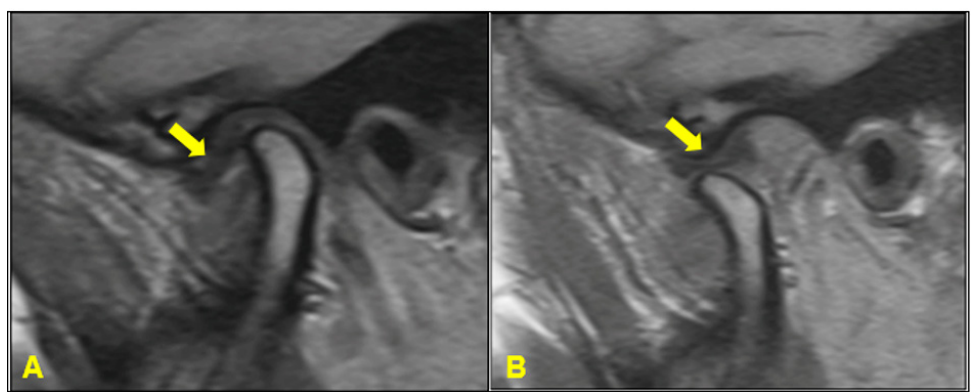

Figure 1- Disc displacement with reduction (DDWR). A: Closed mouth, the articular disc (yellow arrow) is anteriorly displaced in relation to the condyle; B: Open mouth, the disc (yellow arrow) returns to the intermediate area 


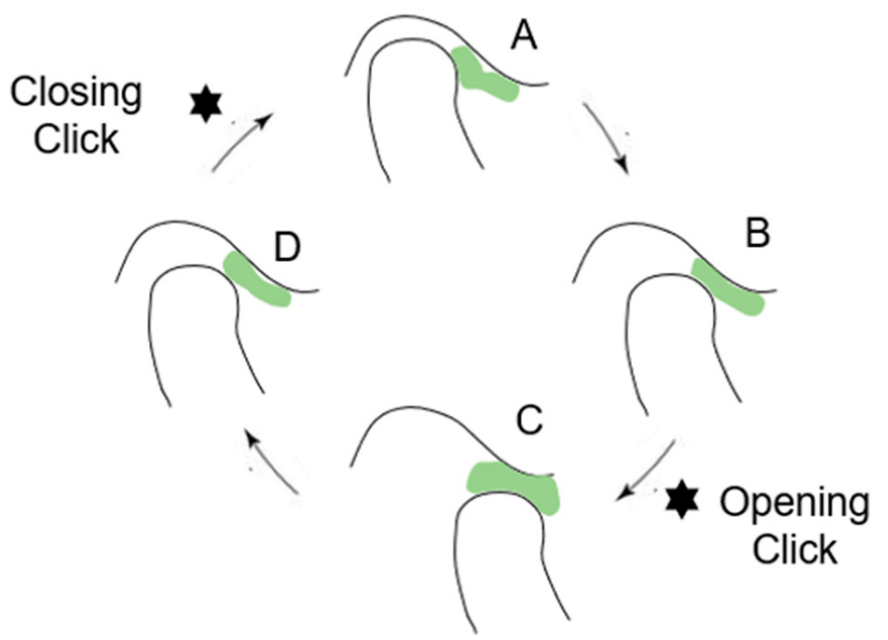

Figure 2- Disc displacement with reduction (DDWR). A: Articular disc anteriorly displaced with retrodiscal fibrosis (red arrow); B: Reduced disc, retrodiscal fibrosis (red arrow)

reduction". Literature reviews, systematic reviews, meta-analysis, observational studies and clinical trials published between March 1987 and June 2018 were included.

\section{Literature review}

\section{Etiology of DDWR}

Etiological factors leading to DDWR are partially attributed to abnormal biomechanical forces applied to the mandibular condyle, which alter the shape and function of the articular tissues. ${ }^{17}$ The literature cites many potential factors that increase the risk of DDWR such as chronic (microtrauma) or acute injuries (macrotrauma) directed against the TMJ, shape and/or dynamic properties alterations of the TMJ components, lack of lubrication, form of the disc modifications, degenerative articular disorder, some occlusal abnormalities, hyperactivity of the lateral pterygoid muscle, joint hypermobility, weakness or laxity of the TMJ ligament and joint capsule. ${ }^{7,17-19}$

The disc-condyle complex derangement comes from the alteration of the relation of the disc on the mandibular condyle. ${ }^{7}$ This loss of normal disc movement can occur when there is elongation of the discal collateral ligaments and the inferior retrodiscal lamina. ${ }^{20}$ Also, a thinning of the posterior border of the disc may allow the disc to be displaced in a more anterior position. ${ }^{20}$ With the condyle resting on a more posterior portion of the disc or retrodiscal tissues, an abnormal translatory shift of the condyle over the posterior border of the disc can occur during opening. ${ }^{20}$ Because the opening movement relocates the disc in the joint, this stage is named DDWR. ${ }^{1,7}$

In the past, it was believed that the disc could be positioned more anteriorly by traction of the lateral pterygoid muscle (LPM). ${ }^{20}$ This theory, however, was disproved based on the assumption that only a small amount of muscle fibers of the LPM are able to transpose the joint capsule and attach directly into the disc. ${ }^{21}$ This weak connection also weakened the theory of LPM muscle contraction involvement in the genesis of disc displacement ${ }^{21}$. In a study with magnetic resonance imaging (MRI), evaluating the correlation between the LPM muscle attachment type and internal derangement of the TMJ, no statistically significant correlation was found. ${ }^{22}$

The prevalence of DDWR is higher in female patients. ${ }^{23}$ This fact may derive from the influence of some female-specific characteristics such as greater joint laxity, ${ }^{24}$ and greater intra-articular pressure. ${ }^{25}$ There is an association between age and DDWR. ${ }^{26} \mathrm{~A}$ multiple logistic regression analysis for DDWR showed that this condition was related to an increased age. ${ }^{27}$ Since joint morphology and intra-articular spatial dimensions change with increasing age, the space insufficiency within the TMJ may develop, leading to a disc positional change. 27,28

TMJ hypermobility, defined as condylar translation beyond the eminence at maximum mouth opening, has also been positively correlated with DDWR. ${ }^{29}$ Occlusal related factors were considered important factors for TMJ internal derangements for a long time. This association, however, has been proved not to be as consistent as thought in the past. By evaluating occlusal factors in children and teenagers (10.8 \pm 3.9 years), a study showed that an increasing overbite 
[odds ratio $(O R)=1.15$ ] could be considered a risk factor for DDWR. ${ }^{30}$ However, in an adult population (32.2 \pm 5.7 years), the contribution of occlusal features to DDWR was considered minimal, with no clinical relevance. $^{31}$

The influence of oral habits on the disc position has also been addressed. An experimental study with DDWR patients submitted to an intensive chewing exercise showed that this activity may strongly delay or even hamper the disc reduction on mouth opening. ${ }^{32}$ Nocturnal tooth grinding has not found to be a risk factor for DDWR. ${ }^{32}$ However, several patients' reports with disc displacement (without distinguishing between those with reduction or without reduction) suggest that clenching and grinding, especially at daytime,

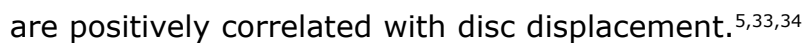
Nevertheless, these finds should be viewed with caution, because none of them used a gold standard tool such as polysomnography or portable diagnostic devices for measuring electromyography activity of masticatory muscles.

TMJ anatomy is also correlated with disc displacement development. Condylar volumes (cortical and trabecular components) are significantly associated with disc displacement and all condylar volumes decrease as disc displacement progress from reduction to non-reduction in both genders. ${ }^{35}$ An association was also observed between the shape of the articular eminence (sigmoid form presented the greatest incidence), disc configuration (biconcave shape was the most common), disc position (anterosuperior position was the most frequent) and DDWR. ${ }^{36,37}$

\section{Natural course of DDWR}

It has been suggested that DDWR would be the first stage of disc displacement, possibly evolving to disc displacement without reduction (DDWoR). ${ }^{38}$ Nevertheless, such observation is not consistent to all conditions and types of DDWR that really evolve to DDWoR. ${ }^{17,39}$ DDWR is considered stable if there are no complaints regarding intermittent locking in patient's history. ${ }^{40}$ Actually, DDWR can remain stable for years depending on adaptive physiological processes that may occur. ${ }^{39}$ The main disc adaptive physiological process is the retrodiscal fibrosis. In a study evaluating $80 \mathrm{TMJ}$ in 40 pain-free individuals (mean age 28.5 years), all TMJs analyzed the retrodiscal fibrosis, being significantly more evident in the 44 TMJs with DDWR. ${ }^{41}$ Fibrosis involves the bilaminar zone of the TMJ as well as the interposed vascular and fatty tissue; it presents a markedly low signal intensity, a homogeneous structure in proximity to the disc, it may not be distinguished from the disc, and has an inhomogeneous aspect, whereas gradually deviating posteriorly from the disc. ${ }^{42}$ It is possible that this retrodiscal fibrosis explains why most DDWR are painless (Figure 3 ).

A study with $81 \mathrm{TMJ}$ from patients with DDWR (mean age 19.65 years) showed no diagnosis change after a follow-up of 9.47 months. ${ }^{43}$ Another study with 92 TMJ from patients with DDWR (mean age 20.76 years) that underwent a follow-up of 9.38 months without treatment, showed that only $6(6.5 \%) \mathrm{TMJ}$ evolved into DDWoR. In the remainder, 86 (93.5\%) DDWR temporomandibular joints, the disc length was evaluated, and the results showed a reduction of $0.66 \pm 0.97 \mathrm{~mm}$ after the follow-up (in the same study, $131 \mathrm{TMJ}$ with DDWoR showed a decrease of $1.36 \pm 1.48 \mathrm{~mm}$ in disc length). ${ }^{44} \mathrm{~A}$ recent longitudinal study showed that of the 155 TMJ that had baseline diagnoses of normal/indeterminate or DDWR (and who received no treatment), 137 (88.4\%) had no change in diagnosis 7.9 years later, on average; this result collaborates with previous studies that state that the classic model of DDWR progression to another internal derangement (such as DDWoR) is uncommon. ${ }^{45}$

A study with 24 patients with DDWR who did not

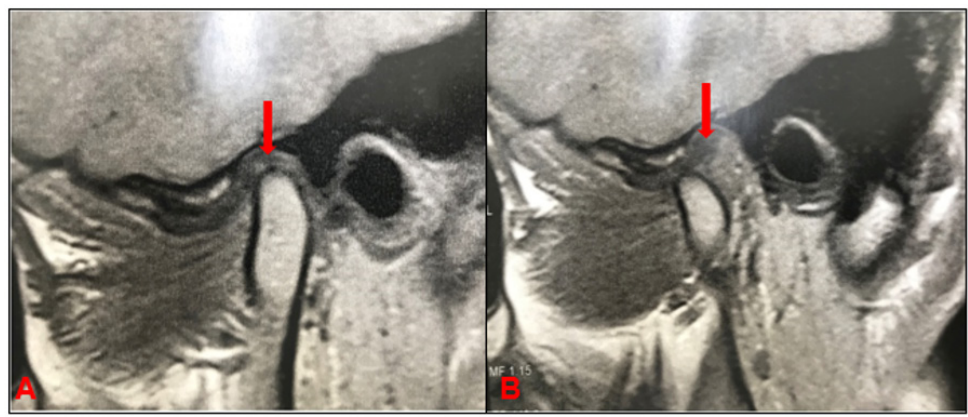

Figure 3- Disc displacement with reduction (DDWR). A: Closed mouth, the articular disc is displaced; B: Mouth opening, followed by an opening click; C: Open mouth, the articular disc is reduced. D: Mouth closing, followed by a closing click 
undergo treatment showed, after 25.8 months of follow-up, that the range of mandibular movement remains unchanged over time and the clicking does not progress to locking in most patients. ${ }^{39}$ Another study, also with a two-year follow-up, showed that the disappearance of clicking associated with DDWR can be related to a gradual loss of the TMJ disc reduction capacity, and that the reports on intermittent locking in patients with DDWR are indicative of the development of DDWoR. However, this loss is only rarely accompanied by symptoms of permanent locking. ${ }^{40}$

Lundh and collegues ${ }^{46}$ (1987), evaluated 70 patients with reciprocal TMJ clicking, during a threeyear follow-up without treatment. Reciprocal clicking remained unchanged in 50 (71\%) and disappeared in 20 patients ( $29 \%)$. Fourteen patients $(20 \%)$, in whom clicking disappeared, attained normal mouth opening, whereas the locking was developed in 6 patients ( $9 \%)$. Another study evaluated the changes in TMJ clicking in 190 subjects with clicking or popping of the TMJ and myofascial pain dysfunction. The patients were originally treated by conservative, nonsurgical modalities that were not specifically directed to the problems of TMJ noise or disc derangement. The follow-up period ranged from 1 to 15 years. In terms of clicking status, 126 patients (63\%) reported cessation or improvement, and 74 patients (36\%) were unchanged. Only three patients described this symptom as worse. ${ }^{47}$

\section{Diagnosis of DDWR}

Many studies have evaluated the diagnostic methods of DDWR. ${ }^{2,48,49}$ MRI is considered the gold standard exam for TMJ conditions, since it allows the simultaneous evaluation of the morphology and position of the articular disc and bone structures of the TMJ, in addition to evaluating the functional relationships between the condyle, articular disc, mandibular fossa, and articular eminence. ${ }^{50} \mathrm{~A}$ multisection analysis of MRI images allows distinguishing the correct disc position from disc displacement and can improve the ability to distinguish between various stages of intra-articular derangement of TMJ. ${ }^{51}$ For DDWR diagnosis, MRI showed a specificity range between 88 and $90 \%$ and sensitivity range between 78 and $83.3 \% .48,52$

Over the last decade, ultrasonography (US) of the TMJ has also been the focus of an increasing number of studies, which aimed to assess the diagnostic accuracy of US for TMJ disc displacement. ${ }^{53}$ Compared to MRI, US showed a sensitivity of $78.6 \%$, specificity of $66.7 \%$, and accuracy of $73.0 \%$ for DDWR diagnosis. ${ }^{54}$ US is a valuable imaging technique in assessing TMJ disc position, however, the diagnostic value of highresolution US depends strictly on the examiner's skills and on the equipment used. ${ }^{55}$ Hence, diagnosis with US still requires standardization of the method as well as further research to confirm its effectiveness. ${ }^{49}$

Manual TMJ inspection is one of the most common techniques to assess TMJ dysfunctions. ${ }^{1,56}$ Because DDWR only becomes clinically relevant when it interferes with TMJ function, the clinical diagnostic approach can be considered a benchmark for DDWR recognition. ${ }^{12}$ The Diagnostic Criteria for Temporomandibular Disorder (DC/TMD), ${ }^{2}$ which is a standardized tool to diagnosis TMD, presents the following diagnosis criteria for DDWR: Positive for at least one of the following: - In the last 30 days, any TMJ noise(s) present with jaw movement or function; OR - Patient report of any noise present during the exam. Positive for at least one of the following: Clicking, popping, and/or snapping noise during both opening and closing movements, detected with palpation during at least one of three repetitions of jaw opening and closing movements; OR - Clicking, popping, and/or snapping noise detected with palpation during at least one of three repetitions of opening or closing movement(s); AND - Clicking, popping, and/ or snapping noise detected with palpation during at least one of three repetitions of right or left lateral, or protrusive movement(s). In a recent meta-analysis, the validity of clinical protocols compared with MRI performed in studies evaluating only DDWR presented sensitivity of $44 \%$ (39 to $49 \%$ ) and specificity of $51 \%$ (46 to $57 \%$ ). The value of the area under the curve for validity of clinical protocols was 0.56 for studies evaluating DDWR. ${ }^{57}$

\section{Treatment of DDWR}

Clinically, DDWR can be considered in three ways: (I) as a clinical finding, when the patient has no complaints and the clicking is identified during the manual professional TMJ inspection or the disc displacement is diagnosed by an MRI examination and only orientations to the patient are sufficient; (II) as the main patient's complaint, when the noise motivates the patient to seek treatment and the treatment 
plan should address options to reduce/eliminate the clicking; (III) when the click is accompanied by arthralgia and the treatment plan should be focused on the amelioration of pain.

Treatment of DDWR, especially when the noise is the complaint, is not an easy task, and for the vast majority of individuals, an explanation of the situation, along with avoidance of overloading activities is the best option. As mentioned above, there is evidence for a self-limiting tendency to this condition, without any kind of clinical conduct or treatment. ${ }^{17,58}$ In absence of complaints, no treatment is recommended. ${ }^{39}$ It is important to remember that there is still no gold standard treatment for TMJ clicking; thus, when patients complain about the noises (clicking) and seek treatment, conservative approaches are always the first choice. ${ }^{17}$

Amongst conservative treatments there are: patient education (such as the explanation about DDWR and orientation of avoidance of excessive open mouth), exercises, relaxation techniques, and occlusal splints. ${ }^{17,59} \mathrm{Au}$ and Klineberg ${ }^{60}$ (1993), used isokinetic exercises of the jaw in 22 patients complaining about TMJ clicking. The exercises included two movement sequences as follows: (1) jaw opening and closing over a distance of $15 \mathrm{~mm}$, and (2) moving the jaw to the left and right over a distance of $5 \mathrm{~mm}$ to each side. Jaw movements were performed against a constant but moderated resistance provided by the subject's hand. After six months of follow-up, the clicking disappeared in approximately $82 \%$ of the patients. Yoda, et al. ${ }^{61}$ (2003), also find a clicking reduction on $61.9 \% \mathrm{TMJ}$ of patients with painless clicking, after three months of therapeutic exercise (protrusion and retrusion). Huang, et al. ${ }^{62}$ (2011), treated 59 patients with painless clicking with a mandibular stabilization occlusal splint (hard acrylic). After six months, there was an elimination of TMJ clicking in $71.2 \%$ of cases. These findings were like those previously found by Conti, et al.63 (2006), who treated with occlusal devices 57 patients with a complaint about TMJ pain and clicking. The patients were divided into three groups: bilateral balanced occlusal splints; canine guidance occlusal splints; and, nonoccluding splint. All subjects had a general improvement on the pain, though subjects in the occlusal splint groups had better results than subjects in the nonoccluding splint group. The frequency of joint noises decreased over time, with no significant differences among groups. In another study, Conti, et al. ${ }^{64}$ (2015) assessed the effectiveness of the partial use of intraoral devices and counseling in the management of 60 patients with DDWR and arthralgia. The patients were equally divided into three groups: group I wore anterior repositioning occlusal splints; group II wore NTI-tss devices, and group III only received counseling for behavioral changes and self-care. The first two groups also received the same counseling. At the beginning of the study, all patients had a TMJ click at least on one side. When joint sounds (clicking) were investigated after 3 months, a decrease in frequency for groups I and III were observed. On the other hand, an increase in frequency for those in group II was detected, although with no significance.

Even though, there is no direct scientific evidence that impaired lubrication of TMJ is indeed responsible for the development of a disc displacement. ${ }^{65}$ Hyaluronic acid (HA), has been suggested as an alternative therapeutic agent for the management of internal TMJ derangements. ${ }^{66}$ Basterzi, et al. ${ }^{67}$ (2009), treated 20 patients with DDWR, with clicking complaint, with intraarticular hyaluronic acid (HA) injections (at weekly intervals for 3 weeks). After one year, there was a significant reduction of joint noises, however, there was no control group without intervention. Korkmaz, et al. ${ }^{68}$ (2016), compared the effectiveness of a single HA injection, a double HA injection, and splint therapy for the treatment of DDWR. The results of this study showed that HA injection and stabilization splinting are acceptably successful modalities of treatment to alleviate the clinical signs and symptoms of DDWR (double HA injection seems to be superior), especially in reducing $\mathrm{TMJ}$ clinking.

Invasive methods should be considered only after failed attempts at conservative care in what concerns persistence of complaints, ${ }^{9}$ and are rarely indicated for DDWR, when noises are considered. These modalities comprise TMJ arthrocentesis, arthroscopies and surgical techniques. ${ }^{17}$ Surgical procedures always involve some risks such as extravasation of liquid to the surrounding tissue, lesion of the facial nerve, optical lesion, pre-auricular hematoma, arteriovenous fistula, trans articular perforation, intracranial perforation, extradural hematoma and post-surgical intra-articular problems, which justify the clinician's caution to recommend any of such procedures as routine or first treatment choice. ${ }^{69,70}$ 


\section{Conclusion}

DDWR is the most common of the TMJ disc displacements. It is commonly an asymptomatic condition and no treatment is usually required, since the structures in this region may adapt and the progression is extremely benign for most cases. Treatment should be done when DDWR is the patient's main complaint, and when the noise motivates the patient to seek treatment and/or the click is accompanied by pain.

\section{Acknowledgment}

Dr. Yuri Martins Costa acknowledges the Section of Head and Face Physiology, Department of Biological Sciences, Bauru School of Dentistry, Universidade de São Paulo, where he was working as a post-doctoral researcher in the course of the preparation and review process of this publication.

\section{References}

1- Leeuw R, Klasser G, editors. Orofacial pain: guidelines for assessment, diagnosis, and management. 6th ed. Chicago: Quintessence; 2018. 2- Schiffman E, Ohrbach R, Truelove E, Look J, Anderson G, Goulet $\mathrm{JP}$, et al. Diagnostic Criteria for Temporomandibular Disorders (DC/ TMD) for clinical and research applications: recommendations of the International RDC/TMD Consortium Network and Orofacial Pain Special Interest Group. J Oral Facial Pain Headache. 2014;28(1):6-27.

3- Murakami S, Takahashi A, Nishiyama H, Fujishita M, Fuchihata $H$. Magnetic resonance evaluation of the temporomandibular joint disc position and configuration. Dentomaxillofac Radiol. 1993;22(4):205-7. 4- Talaat WM, Adel OI, Al Bayatti S. Prevalence of temporomandibular disorders discovered incidentally during routine dental examination using the Research Diagnostic Criteria for Temporomandibular Disorders. Oral Surg Oral Med Oral Pathol Oral Radiol. 2017;125(3):250-9.

5- Katzberg RW, Westesson PL, Tallents RH, Drake CM. Anatomic disorders of the temporomandibular joint disc in asymptomatic subjects. J Oral Maxillofac Surg. 1996;54(2):147-53.

6- Ahmad M, Hollender L, Anderson Q, Kartha K, Ohrbach R, Truelove $E L$, et al. Research Diagnostic Criteria for Temporomandibular Disorders (RDC/TMD): development of image analysis criteria and examiner reliability for image analysis. Oral Surg Oral Med Oral Pathol Oral Radiol Endod. 2009;107(6):844-60.

7- De Leeuw R. Intra-articular derangements of the temporomandibular joint. Oral Maxillofac Surg Clin North Am. 2008;20(2):159-68.

8- Tasaki MM, Westesson PL, Isberg AM, Ren YF, Tallents RH. Classification and prevalence of temporomandibular joint disk displacement in patients and symptom-free volunteers. Am J Orthod Dentofacial Orthop. 1996;109(3):249-62.

9- Young AL. Internal derangements of the temporomandibular joint: a review of the anatomy, diagnosis, and management. J Indian Prosthodont Soc. 2015;15(1):2-7.

10- Sener S, Akgänlü F. MRI characteristics of anterior disc displacement with and without reduction. Dentomaxillofac Radiol. 2004;33(4):24552.
11- Elfving L, Helkimo M, Magnusson T. Prevalence of different temporomandibular joint sounds with emphasis on disk displacement, in patients with temporomandibular disorders and controls. Swed Dent J. $2002 ; 26(1): 9-19$

12- Marpaung CM, Kalaykova SI, Lobbezoo F, Naeije M. Validity of functional diagnostic examination for temporomandibular joint disc displacement with reduction. J Oral Rehabil. 2014;41(4):243-9.

13- Jussila $P$, Kiviahde $H$, Näpänkangas R, Päkkilä J, Pesonen $P$, Sipilä $\mathrm{K}$, et al. Prevalence of temporomandibular disorders in the Northern Finland Birth Cohort 1966. J Oral Facial Pain Headache. 2017;31(2):159-64

14- Ukra A, Foster Page LA, Thomson WM, Knight RG, Farella M. Selfreport of temporomandibular joint clicking and psychological factors: is there an association? J Oral Rehabil. 2017;44(7):511-6.

15- Koh KJ, Park HN, Kim KA. Internal derangement as a predictor of provoked pain on mouth opening: a magnetic resonance imaging study. Imaging Sci Dent. 2017;47(4):219-26.

16- Cunha CO, Pinto-Fiamengui LM, Castro AC, Lauris JR, Conti PC. Determination of a pressure pain threshold cut-off value for the diagnosis of temporomandibular joint arthralgia. J Oral Rehabil. 2014;41(5):323-9.

17- Lalue-Sanches M, Gonzaga AR, Guimarães AS, Ribeiro EC. Disc displacement with reduction of the temporomandibular joint: the real need for treatment. J Pain Relief. 2015;4(5):2-5.

18- Manfredini D. Etiopathogenesis of disc displacement of the temporomandibular joint: a review of the mechanisms. Indian J Dent Res 2009;20(2):212-21.

19- Okeson JP. Joint intracapsular disorders: diagnostic and nonsurgical management considerations. Dent Clin North Am. 2007; 51(1):85-103. 20- Murray GM, Bhutada M, Peck CC, Phanachet I, Sae-Lee D, Whittle T. The human lateral pterygoid muscle. Arch Oral Biol. 2007;52(4):37780.

21- Murray GM, Phanachet I, Uchida S, Whittle T. The human latera pterygoid muscle: a review of some experimental aspects and possible clinical relevance. Aust Dent J. 2004;49(1):2-8

22- Dergin G, Kilic C, Gozneli R, Yildirim D, Garip H, Moroglu S. Evaluating the correlation between the lateral pterygoid muscle attachment type and internal derangement of the temporomandibular joint with an emphasis on MR imaging findings. J Craniomaxillofac Surg. 2012;40(5):459-63

23- Lazarin RO, Previdelli IT, Silva RS, Iwaki LC, Grossmann E, Iwak Filho L. Correlation of gender and age with magnetic resonance imaging findings in patients with arthrogenic temporomandibular disorders: a cross-sectional study. Int J Oral Maxillofac Surg. 2016;45(10):1222-8. 24- McCarroll RS, Hesse JR, Naeije M, Yoon CK, Hansson TL. Mandibular border positions and their relationships with peripheral joint mobility. J Oral Rehabil. 1987;14(2):125-31.

25- Nitzan DW. Intraarticular pressure in the functioning human temporomandibular joint and its alteration by uniform elevation of the occlusal plane. J Oral Maxillofac Surg. 1994;52(7):671-9.

26- Ikeda K, Kawamura A, Ikeda R. Prevalence of disc displacement of various severities among young preorthodontic population: a magnetic resonance imaging study. J Prosthodont. 2014;23(5):397-401.

27- Kalaykova SI, Lobbezoo F, Naeije M. Risk factors for anterior disc displacement with reduction and intermittent locking in adolescents. J Orofac Pain. 2011;25(2):153-60.

28- Katsavrias EG. Changes in articular eminence inclination during the craniofacial growth period. Angle Orthod. 2002;72(3):258-64 29- Johansson AS, Isberg A. The anterosuperior insertion of the temporomandibular joint capsule and condylar mobility in joints with and without internal derangement: a double contrast arthrotomographic investigation. J Oral Maxillofac Surg. 1991;49(11):1142-8 
30- Huddleston Slater JJ, Lobbezoo F, Onland-Moret NC, Naeije M. Anterior disc displacement with reduction and symptomatic hypermobility in the human temporomandibular joint: prevalence rates and risk factors in children and teenagers. J Orofac Pain. 2007;21(1):55-62.

31- Manfredini D, Perinetti G, Guarda-Nardini L. Dental malocclusion is not related to temporomandibular joint clicking: a logistic regression analysis in a patient population. Angle Orthod. 2014;84(2):310-5. 32- Kalaykova S, Lobbezoo F, Naeije M. Effect of chewing upon disc reduction in the temporomandibular joint. J Orofac Pain. 2011;25(1):49-55.

33- Velly AM, Gornitsky M, Philippe P. A case-control study of temporomandibular disorders: symptomatic disc displacement. J Oral Rehabil. 2002;29(5):408-16.

34- Michelotti A, Cioffi I, Festa P, Scala G, Farella M. Oral parafunctions as risk factors for diagnostic TMD subgroups. J Oral Rehabil. 2010;37(3):157-62.

35- Ahn SJ, Chang MS, Choi JH, Yang IH, An JS, Heo MS. Relationships between temporomandibular joint disc displacements and condylar volume. Oral Surg Oral Med Oral Pathol Oral Radiol. 2018;125(2):192-

8.

36- Farias JF, Melo SL, Bento PM, Oliveira LS, Campos PS, Melo DP. Correlation between temporomandibular joint morphology and disc displacement by MRI. Dentomaxillofac Radiol. 2015;44(7):20150023. 37- Hirata FH, Guimarães AS, Oliveira JX, Moreira CR, Ferreira ET, Cavalcanti MG. Evaluation of TMJ articular eminence morphology and disc patterns in patients with disc displacement in MRI. Braz Oral Res. 2007;21(3):265-71.

38- Huddleston Slater JJ, Lobbezoo F, Chen YJ, Naeije M. A comparative study between clinical and instrumental methods for the recognition of internal derangements with a clicking sound on condilar movements. J Orofac Pain. 2004;18(2):138-47.

39- Sato S, Goto S, Nasu F, Motegi K. Natural course of disc displacement with reduction of the temporomandibular joint: changes in clinical signs and symptoms. J Oral Maxillofac Surg. 2003;61(1):32-4. 40- Kalaykova S, Lobbezoo F, Naeije M. Two-year natural course of anterior disc displacement with reduction. J Orofac Pain. 2010;24(4):373-8.

41- Mazza D, Stasolla A, Kharrub Z, Maccioni F, Marini M. MRI evaluation of morpho-structural alterations of the retrodiscal tissue in condylomeniscal incoordination of the TMJ: usefulness of individualised T2weighted TSE sequences. Radiol Med. 2004;107(3):261-8.

42- Segù M, Politi L, Galioto S, Collesano V. Histological and functional changes in retrodiscal tissue following anterior articular disc displacement in the rabbit: review of the literature. Minerva Stomatol. 2011;60(7-8):349-58.

43- Hu YK, Yang C, Cai XY, Xie QY. Does condylar height decrease more in temporomandibular joint nonreducing disc displacement than reducing disc displacement?: a magnetic resonance imaging retrospective study. Medicine (Baltimore). 2016;95(35):e4715.

44- Hu YK, Yang C, Xie QY. Changes in disc status in the reducing and nonreducing anterior disc displacement of temporomandibular joint: a longitudinal retrospective study. Sci Rep. 2016;6(1):34253.

45- Schiffman EL, Ahmad M, Hollender L, Kartha K, Ohrbach R, Truelove $\mathrm{EL}$, et al. Longitudinal stability of common TMJ structural disorders. J Dent Res. 2017;96(3):270-6.

46- Lundh $\mathrm{H}$, Westesson PL, Kopp S. A three-year follow-up of patients with reciprocal temporomandibular joint clicking. Oral Surg Oral Med Oral Pathol. 1987;63(5):530-3.

47- Greene CS, Laskin DM. Long-term status of TMJ clicking in patients with myofascial pain and dysfunction. J Am Dent Assoc. $1988 ; 117(3): 461-5$.

48- Vogl TJ, Lauer HC, Lehnert T, Naguib NN, Ottl P, Filmann N, et al. The value of MRI in patients with temporomandibular joint dysfunction: correlation of MRI and clinical findings. Eur J Radiol. 2016;85(4):714-9.
49- Klatkiewicz T, Gawriołek K, Pobudek Radzikowska M, CzajkaJakubowska A. Ultrasonography in the diagnosis of temporomandibular disorders: a meta-analysis. Med Sci Monit. 2018;24(1):812-7.

50- Yang Z, Wang M, Ma Y, Lai Q, Tong D, Zhang F, et al. Magnetic resonance imaging (MRI) evaluation for anterior disc displacement of the temporomandibular joint. Med Sci Monit. 2017;23(8):712-8. 51- Litko M, Berger M, Szkutnik J, Różyło-Kalinowska I. Correlation between direction and severity of temporomandibular joint disc displacement and reduction ability during mouth opening. J Oral Rehabil. 2017;44(12):957-63.

52- Kumar R, Pallagatti S, Sheikh S, Mittal A, Gupta D, Gupta $S$. Correlation between clinical findings of temporomandibular disorders and MRI characteristics of disc displacement. Open Dent J. 2015;9(31):273-81

53- Li C, Su N, Yang X, Yang X, Shi Z, Li L. Ultrasonography for detection of disc displacement of temporomandibular joint: a systematic review and meta-analysis. J Oral Maxillofac Surg. 2012;70(6):1300-9.

54- Habashi H, Eran A, Blumenfeld I, Gaitini D. Dynamic high-resolution sonography compared to magnetic resonance imaging for diagnosis of temporomandibular joint disc displacement. J Ultrasound Med. 2015;34(1):75-82.

55- Talmaceanu D, Lenghel LM, Bolog N, Popa Stanila R, Buduru $S$, Leucuta $D C$, et al. High-resolution ultrasonography in assessing temporomandibular joint disc position. Med Ultrason. 2018;1(1):64-70. 56- Manfredini D, Guarda-Nardini L. Agreement between Research Diagnostic Criteria for Temporomandibular Disorders and magnetic resonance diagnoses of temporomandibular disc displacement in a patient population. Int J Oral Maxillofac Surg. 2008;37(7):612-6. 57- Pupo YM, Pantoja LL, Veiga FF, Stechman-Neto J, Zwir LF, Farago PV, et al. Diagnostic validity of clinical protocols to assess temporomandibular disk displacement disorders: a meta-analysis. Oral Surg Oral Med Oral Pathol Oral Radiol. 2016;122(5):572-86. 58- Garefis P, Grigoriadou E, Zarifi A, Koidis PT. Effectiveness of conservative treatment for craniomandibular disorders: a 2-year longitudinal study. J Orofac Pain. 1994;8(3):309-14.

59- Gil-Martínez A, Paris-Alemany A, López-de-Uralde-Villanueva I, La Touche R. Management of pain in patients with temporomandibular disorder (TMD): challenges and solutions. J Pain Res. 2018;11(1):57187.

60- Au AR, Klineberg IJ. Isokinetic exercise management of temporomandibular joint clicking in young adults. J Prosthet Dent. 1993;70(1):33-9.

61- Yoda T, Sakamoto I, Imai H, Honma Y, Shinjo Y, Takano A, et al. A randomized controlled trial of therapeutic exercise for clicking due to disc anterior displacement with reduction in the temporomandibular joint. Cranio. 2003;21(1):10-6.

62- Huang IY, Wu JH, Kao YH, Chen CM, Chen CM, Yang YH. Splint therapy for disc displacement with reduction of the temporomandibular joint. Part I: modified mandibular splint therapy. Kaohsiung J Med Sci. 2011;27(8):323-9.

63- Conti PC, Santos CN, Kogawa EM, Castro Ferreira Conti AC, Araujo $C R$. The treatment of painful temporomandibular joint clicking with oral splints: a randomized clinical trial. J Am Dent Assoc. 2006;137(8):1108-14.

64- Conti PC, Corrêa AS, Lauris JR, Stuginski-Barbosa J. Management of painful temporomandibular joint clicking with different intraoral devices and counseling: a controlled study. J Appl Oral Sci. 2015;23(5):529-35. 65- Naeije M, Te Veldhuis AH, Te Veldhuis EC, Visscher CM, Lobbezoo F. Disc displacement within the human temporomandibular joint: a systematic review of a "noisy annoyance". J Oral Rehabil. 2013;40(2):139-58

66- Goiato MC, Silva EV, Medeiros RA, Túrcio KH, Santos DM. Are intra-articular injections of hyaluronic acid effective for the treatment of temporomandibular disorders? A systematic review. Int J Oral Maxillofac Surg. 2016;45(12):1531-7. 
67- Basterzi Y, Sari A, Demirkan F, Unal S, Arslan E. Intraarticular hyaluronic acid injection for the treatment of reducing and nonreducing disc displacement of the temporomandibular joint. Ann Plast Surg. 2009;62(3):265-7.

68- Korkmaz YT, Altıntas NY, Korkmaz FM, Candırlı C, Coskun U, Durmuslar MC. Is hyaluronic acid injection effective for the treatment of temporomandibular joint disc displacement with reduction? J Oral Maxillofac Surg. 2016;74(9):1728-40.
69- Alpaslan GH, Alpaslan C. Efficacy of temporomandibular joint arthrocentesis with and without injection of sodium hyaluronate in treatment of internal derangements. J Oral Maxillofac Surg. 2001;59(6):613-8.

70- Guarda-Nardini L, Manfredini D, Ferronato G. Short-term effects of arthrocentesis plus viscosupplementation in the management of signs and symptoms of painful TMJ disc displacement with reduction. A pilot study. Oral Maxillofac Surg. 2010;14(1):29-34.

\section{Erratum}

Due to a publishing error the article: "Temporomandibular joint disc displacement with reduction: a review of mechanisms and clinical presentation", published at Journal of Applied Oral Science 27(e-20180433):1-9 was printed with the following error:

\section{Where its reads}

Page

$3 / 9$

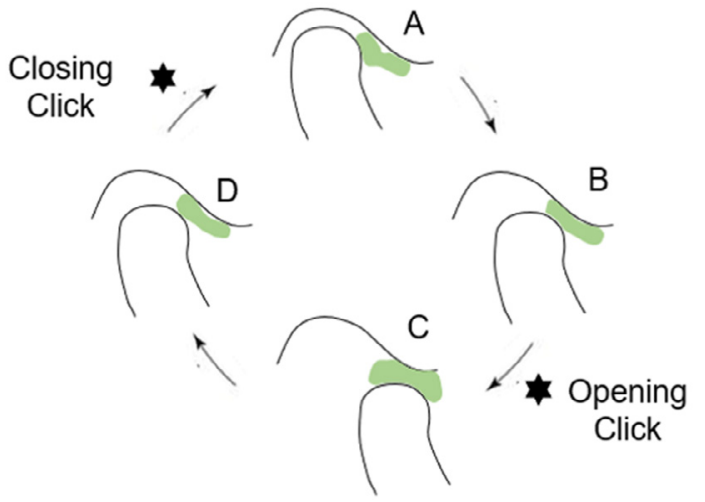

Figure 2- Disc displacement with reduction (DDWR). A: Articular disc anteriorly displaced with retrodiscal fibrosis (red arrow); B: Reduced disc, retrodiscal fibrosis (red arrow)

\section{Where its reads}

Page $4 / 9$

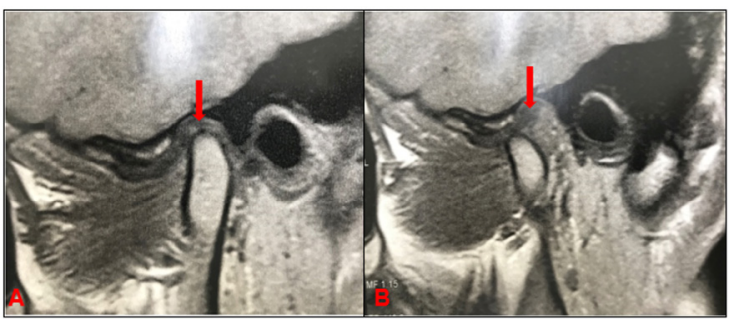

Figure 3- Disc displacement with reduction (DDWR). A: Closed mouth, the articular disc is displaced; B: Mouth opening, followed by an opening click; C: Open mouth, the articular disc is reduced. D: Mouth closing, followed by a closing click

\section{The sentence should read}

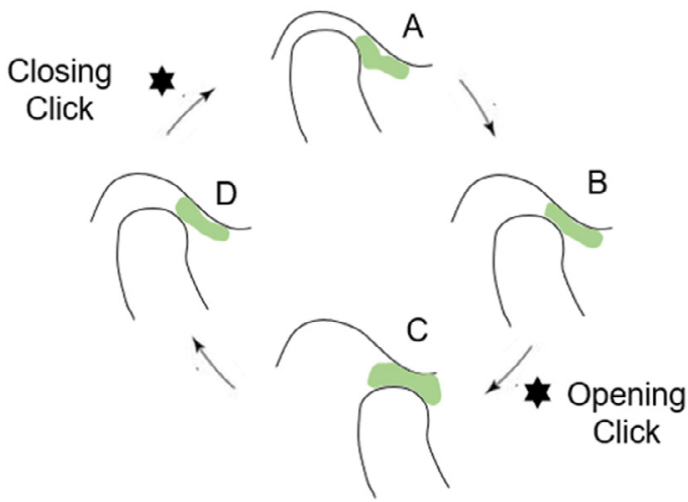

Figure 2- Disc displacement with reduction (DDWR). A: Closed mouth, the articular disc is displaced; B: Mouth opening, followed by an opening click; C: Open mouth, the articular disc is reduced. D: Mouth closing, followed by a closing click

\section{The sentence should read}

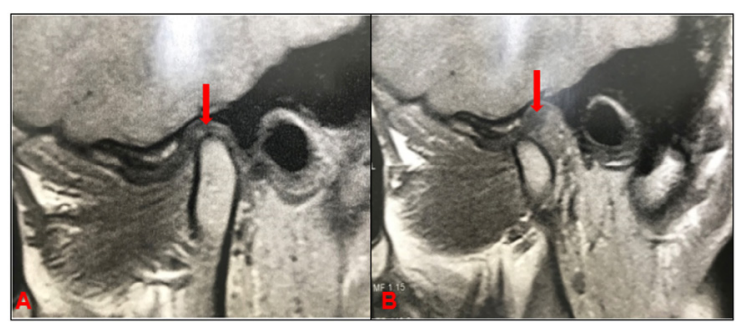

Figure 3- Disc displacement with reduction (DDWR). A Articular disc anteriorly displaced with retrodiscal fibrosis (red arrow); B: Reduced disc, retrodiscal fibrosis (red arrow) 